\title{
Novel Hexagonal Structure of Ultra-High Strength Magnesium-Based Alloys
}

\author{
Akihisa Inoue $^{1}$, Mitsuhide Matsushita ${ }^{2}$, Yoshihito Kawamura ${ }^{1}$, Kenji Amiya ${ }^{2}$, \\ Kentaro Hayashi ${ }^{1, *}$ and Junich Koike ${ }^{3}$ \\ ${ }^{1}$ Institute for Materials Research, Tohoku University, Sendai 980-8577, Japan \\ ${ }^{2}$ Inoue Superliquid Glass Project, Exploratory Research for Advanced Technology, \\ Japan Science and Technology Corporation, Sendai 982-0807, Japan \\ ${ }^{3}$ Materials Science and Engineering, Tohoku University, Sendai 980-8579, Japan
}

\begin{abstract}
A magnesium $\left(\mathrm{Mg}\right.$ ) solid solution with a novel long periodic hexagonal structure was formed for a $\mathrm{Mg}_{97} \mathrm{Zn}_{1} \mathrm{Y}_{2}$ (at\%) alloy in a rod form prepared by extrusion of atomized powders at $573 \mathrm{~K}$ as well as in a melt-spun ribbon form. The novel structure of the rod alloy had an ABACAB-type six layered packing with lattice parameters of $a=0.322 \mathrm{~nm}$ and $c=3 \times 0.521 \mathrm{~nm}$. The Mg phase in the extruded rod alloy had fine grain sizes of 100 to $150 \mathrm{~nm}$ and included cubic $\mathrm{Mg}_{24} \mathrm{Y}_{5}$ particles with a size of about $10 \mathrm{~nm}$ at volume fractions below $10 \%$. The density $(\rho)$ was $1.84 \mathrm{Mg} / \mathrm{m}^{3}$. The tensile yield strength $\left(\sigma_{\mathrm{y}}\right)$ and elongation of the rod alloy were $610 \mathrm{MPa}$ and $5 \%$, respectively, and the specific strength defined by the ratio of $\sigma_{\mathrm{y}}$ to $\rho$ was $330 \mathrm{MPa} /\left(\mathrm{Mg} / \mathrm{m}^{3}\right)$, being the highest among all metallic alloys. The $\sigma_{\mathrm{y}}$ is 2.7 to 8 times higher than those for conventional high-strength Mg-based alloys. The excellent mechanical properties are due to the combination of fine grain size, new long periodic hexagonal solid solution, homogeneous dispersion of fine $\mathrm{Mg}_{24} \mathrm{Y}_{5}$ particles inside the nano-grains and the absence of the second precipitates along the grain boundary. The new Mg-based alloy is promising for future uses in many fields.
\end{abstract}

(Received October 5, 2001; Accepted January 30, 2002)

Keywords: magnesium base alloy, hexagonal phase, long periodic atomic configuration, rapid solidification, extruded bulk alloy, high strength, good ductility

\section{Introduction}

In recent years, there have been strong demands of energy saving and maintenance of a clean atmosphere on earth. One of the ways which satisfy with these demands is to fabricate an ultra-high strength material with light specific weight by using raw materials which are abundant resources and have high recycling ratios. Mg metal with a hexagonal closed packed (hcp) structure has a low specific weight of $1.74 \mathrm{Mg} / \mathrm{m}^{3}$ and is one of abundant metals on earth. ${ }^{1)}$ It is well known that $\mathrm{Mg}$-based alloys belong to an easy recycling material. Owing to these social demands and advantages, $\mathrm{Mg}$ based alloys have been used in various fields, e.g., case materials for television, camera, portable telephone and word processor and part materials in automobile and bicycle. ${ }^{1)}$ However, the tensile yield strength and elongation of conventional Mg-based alloys are 70 to $180 \mathrm{MPa}$ and 2 to $10 \%$, respectively, for casting-type and 90 to $230 \mathrm{MPa}$ and 4 to $13 \%$, respectively, for heat treatment type. ${ }^{1)}$

We have examined structure, strength and ductility of $\mathrm{Mg}$ based solid solutions in ternary systems such as $\mathrm{Mg}-\mathrm{Ca}-\mathrm{Al}$, $\mathrm{Mg}-\mathrm{Al}-\mathrm{Zn}, \mathrm{Mg}-\mathrm{Al}-\mathrm{Y}$ and $\mathrm{Mg}-\mathrm{Zn}-\mathrm{Y}$ etc. where the three elements have significant atomic size mismatches above $12 \%$ and negative heats of mixing. The combination of such three elements is expected to cause an anomaly in the structure and properties of the multi-component solid solution. This is because the ternary alloys have anomalous effects such as stabilization of supercooled liquid and high glass-forming ability which enable us to form bulk glassy alloys. ${ }^{2-4)}$ As an anomalous result, we fabricated an ultra-high strength $\mathrm{Mg}$ based $\mathrm{Mg}_{97} \mathrm{Zn}_{1} \mathrm{Y}_{2}$ alloy with a novel long periodic hexagonal structure by the warm extrusion process of atomized powders (RS/PM). ${ }^{5)}$ The formation of the novel hexagonal Mg- based phase was subsequently recognized in the melt-spun $\mathrm{Mg}_{97} \mathrm{Zn}_{1} \mathrm{Y}_{2}$ alloy. This paper intends to present the novel structure of the RS/PM $\mathrm{Mg}_{97} \mathrm{Zn}_{1} \mathrm{Y}_{2}$ alloy with high strength and good ductility in comparison with the structures of the melt-spun $\mathrm{Mg}-\mathrm{Zn}-\mathrm{Y}, \mathrm{Mg}-\mathrm{Al}-\mathrm{Y}, \mathrm{Mg}-\mathrm{Y}$ and $\mathrm{Mg}-\mathrm{Zn}$ alloy ribbons.

\section{Experimental Procedure}

Ternary $\mathrm{Mg}_{100-x-y} \mathrm{Zn}_{x} \mathrm{Y}_{y}$ alloy ingots were prepared by induction heating the mixtures of pure metals in a flowing argon atmosphere. Binary $\mathrm{Mg}_{98} \mathrm{Zn}_{2}$ and $\mathrm{Mg}_{98} \mathrm{Y}_{2}$ and ternary $\mathrm{Mg}_{97} \mathrm{Al}_{1} \mathrm{Y}_{2}$ alloys were also prepared for comparison. The alloy compositions represent nominal atomic percentages. Ribbon samples with a cross section of about $0.2 \times 1.2 \mathrm{~mm}^{2}$ were produced by melt spinning. Ductility and hardness of the ribbons were measured by the simple bend test and Vickers micro-hardness test with a load of $50 \mathrm{~g}$, respectively. Alloy powders were produced by helium gas atomization with a pressure of 9.8 $\mathrm{MPa}$ and then sieved to the size fraction below $32 \mu \mathrm{m}$. The sieved powder was pre-compacted into a copper can, followed by evacuating and then sealing. The sealed powder was extruded at a reduction ratio of 10 and at temperatures between 573 and $723 \mathrm{~K}$. The extruded alloy had a rod shape of $6 \mathrm{~mm}$ in diameter. The structures of the extruded rods as well as the melt-spun ribbons were examined by $\mathrm{X}$ ray diffraction, transmission electron microscopy (TEM) and high-resolution TEM and atomic component was determined by energy dispersive X-ray (EDX) spectroscopy. Mechanical properties were measured with an Instron testing machine at a strain rate of $5.0 \times 10^{-4} \mathrm{~s}^{-1}$. The gauge dimension of the tensile specimens was $25 \mathrm{~mm}$ in length and $2 \mathrm{~mm}$ in diameter. 


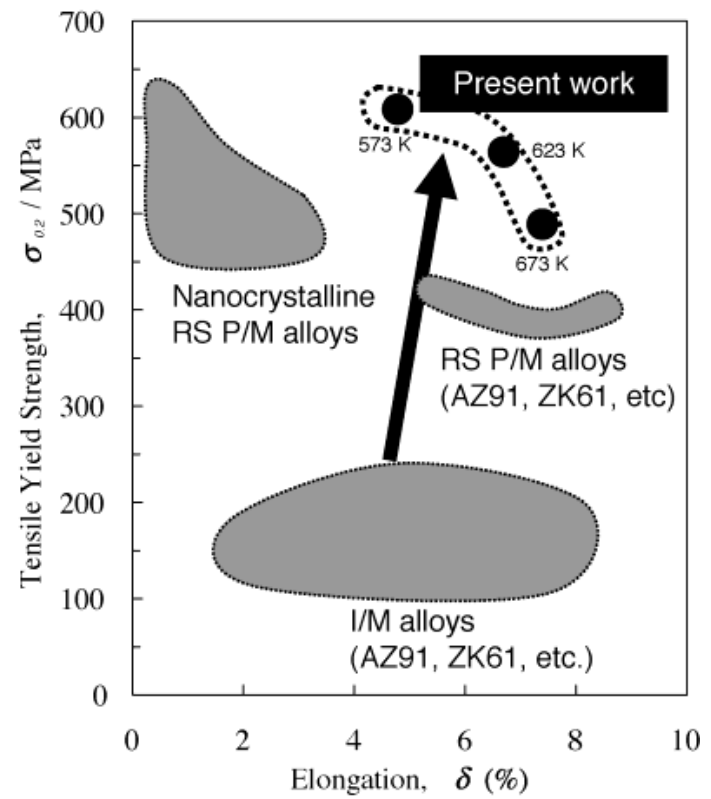

Fig. 1 Relation between tensile yield strength and elongation for the $\mathrm{RS} / \mathrm{PM} \mathrm{Mg} \mathrm{M}_{97} \mathrm{Zn}_{1} \mathrm{Y}_{2}$ alloy rods produced at various extrusion temperatures $\left(T_{\mathrm{e}}\right)$. The data of $\mathrm{Mg}$-based alloys produced by ingot metallurgy (IM) and heat treatment (aging) as well as previously developed RS/PM Mg-based alloys ${ }^{6)}$ are also shown for comparison.

\section{Results}

The melt-spun $\mathrm{Mg}_{97} \mathrm{Zn}_{1} \mathrm{Y}_{2}$ alloy had the highest hardness in conjunction with good bend ductility after annealing for $1.2 \mathrm{ks}$ at 573 and $673 \mathrm{~K}$ corresponding to the extrusion temperatures of the atomized powders. Consequently, we chose the $\mathrm{Mg}_{97} \mathrm{Zn}_{1} \mathrm{Y}_{2}$ alloy for the formation of bulk alloys by the $\mathrm{RS} / \mathrm{PM}$ process. Figure 1 shows the relation between tensile yield strength $\left(\sigma_{\mathrm{y}}\right)$ and elongation $(\delta)$ for the $\mathrm{Mg}-\mathrm{Zn}-\mathrm{Y}$ alloy rods produced by extrusion at different temperatures, together with Mg-based alloys developed up to date. It is noticed that the $\sigma_{\mathrm{y}}$ and $\delta$ of the RS/PM alloy rods are two to three times higher than those for the Mg-based alloys marked with ingot metallurgy (I/M) and heat treatment (aging). Even in comparison with the Mg-based alloys developed previously by the same RS/PM process, ${ }^{6)}$ the $\sigma_{\mathrm{y}}$ values of the present alloy rods are higher by 1.5 times. The Young's modulus $(E)$ was $41 \mathrm{GPa}$ for the RS/PM alloy with $\sigma_{\mathrm{y}}$ of $610 \mathrm{MPa}$. Figure 2 shows the specific yield strength $\left(\sigma_{\mathrm{y}} / \rho\right)$ and specific modulus $(E / \rho)$ of the RS/PM $\mathrm{Mg}_{97} \mathrm{Zn}_{1} \mathrm{Y}_{2}$ alloy rod prepared by extrusion at $573 \mathrm{~K}$ in comparison with other conventional Mg-, Aland Ti-based alloys. The density of the RS/PM $\mathrm{Mg}_{97} \mathrm{Zn}_{1} \mathrm{Y}_{2}$ alloy was $1.84 \mathrm{Mg} / \mathrm{m}^{3}$. It is noticed that the $\mathrm{Mg}_{97} \mathrm{Zn}_{1} \mathrm{Y}_{2}$ alloy has the highest $\sigma_{\mathrm{y}} / \rho$ value among all metallic alloys and the increase ratio reaches 4 times as compared with conventional Mg-based alloys.

The reason for the excellent mechanical properties was investigated by examining microstructure of the $\mathrm{Mg}_{97} \mathrm{Zn}_{1} \mathrm{Y}_{2}$ alloy produced at $T_{\mathrm{e}}=573 \mathrm{~K}$. Figure 3(a) shows its bright-field TEM image. The grain size is as small as 100 to $150 \mathrm{~nm}$. In addition, one can see a high density of plane faults and fine precipitates with a rectangular shape in almost all the grains, while no appreciable precipitates are observed on the grain boundary. Figures 3(b) and (c) show the high-resolution TEM image and selected-area electron diffraction pattern of the ma-

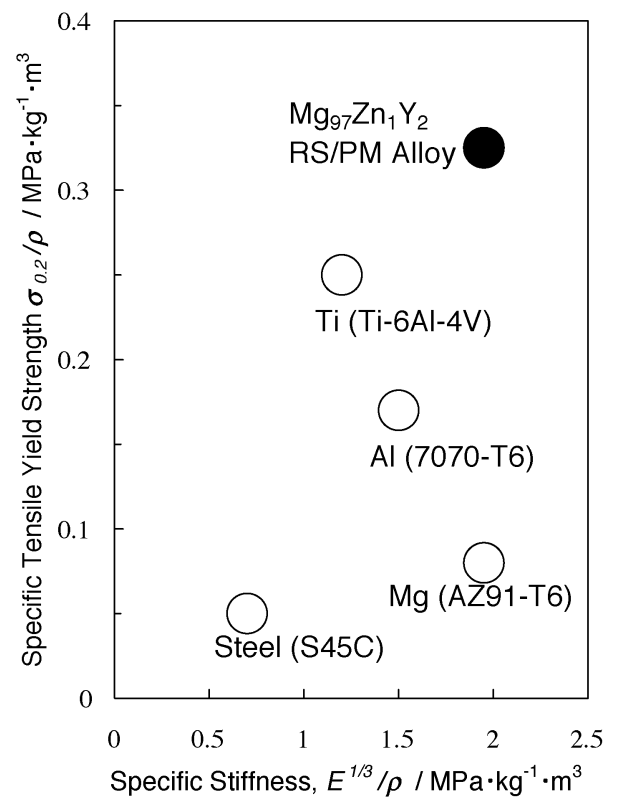

Fig. 2 Specific yield strength $\left(\sigma_{\mathrm{y}} / \rho\right)$ and specific Young's modulus $(E / \rho)$ for the RS/PM $\mathrm{Mg}_{97} \mathrm{Zn}_{1} \mathrm{Y}_{2}$ alloy rod produced at $T_{\mathrm{e}}=573 \mathrm{~K}$ in comparison with other conventional alloys.

trix phase including a high density of plane faults. In (c) revealing the hexagonal structure, one can see extra reflection spots at the positions of $1 / 3(0001)_{\mathrm{Mg}}$ and $2 / 3(0001)_{\mathrm{Mg}}$ and strong streaks along the $[0001]_{\mathrm{Mg}}$ direction. This reveals that the Mg-based solid solution includes a high density of plane faults along the $(0001)_{\mathrm{Mg}}$ plane. The diffraction pattern also indicates the formation of a new hexagonal structure with lattice parameters of $a=0.322 \mathrm{~nm}$ and $c=3 \times 0.521 \mathrm{~nm}$. The $c$ value is three times longer than that of the ordinary hcp $\mathrm{Mg}$ phase. It was confirmed from the EDX spectrum that the $\mathrm{Mg}$ phase was a solid solution containing 0.78 at $\% \mathrm{Zn}$ and 1.82 at\% Y. Figure 4 shows a high-resolution TEM image of the plane-faulted region. The long periodic hexagonal phase has a six layered atomic packing of $\mathrm{ABACAB}$ type which is three times longer than the AB-type two layered atomic configuration in the ordinary $\mathrm{Mg}$ metal. The change to the long periodic hexagonal packing is presumed to result from strains generated by the reinforced solution of $\mathrm{Y}$ and $\mathrm{Zn}$ into hcp $\mathrm{Mg}$ phase. This is the first evidence for the formation of the new long periodic hexagonal structure for the Mg-based solid solution. We have also confirmed from the nanobeam electron diffraction pattern and EDX spectrum that the rectangular precipitate is a cubic $\mathrm{Mg}_{24} \mathrm{Y}_{5}$ phase with a lattice parameter of $1.1 \mathrm{~nm}$.

In this paper, it is important to examine the formation condition of the novel long periodic hexagonal phase. The novel phase was also observed in the melt-spun $\mathrm{Mg}_{97} \mathrm{Zn}_{1} \mathrm{Y}_{2}$ ribbon alloy. Figure 5 shows a bright-field image and a selectedarea electron diffraction pattern taken from grain $\mathrm{A}$ for the melt-spun $\mathrm{Mg}_{97} \mathrm{Zn}_{1} \mathrm{Y}_{2}$ alloy ribbon. The average grain size of the matrix phase is about $1000 \mathrm{~nm}$ which is about one order larger than that for the RS/PM alloy. One can see a high density of plane faults in the grains marked with A and B. In addition, extra reflection spots are seen along the $[0001]_{\mathrm{Mg}}$ direction in the electron diffraction pattern. The features of the plane faults and extra reflection spots are analogous to 

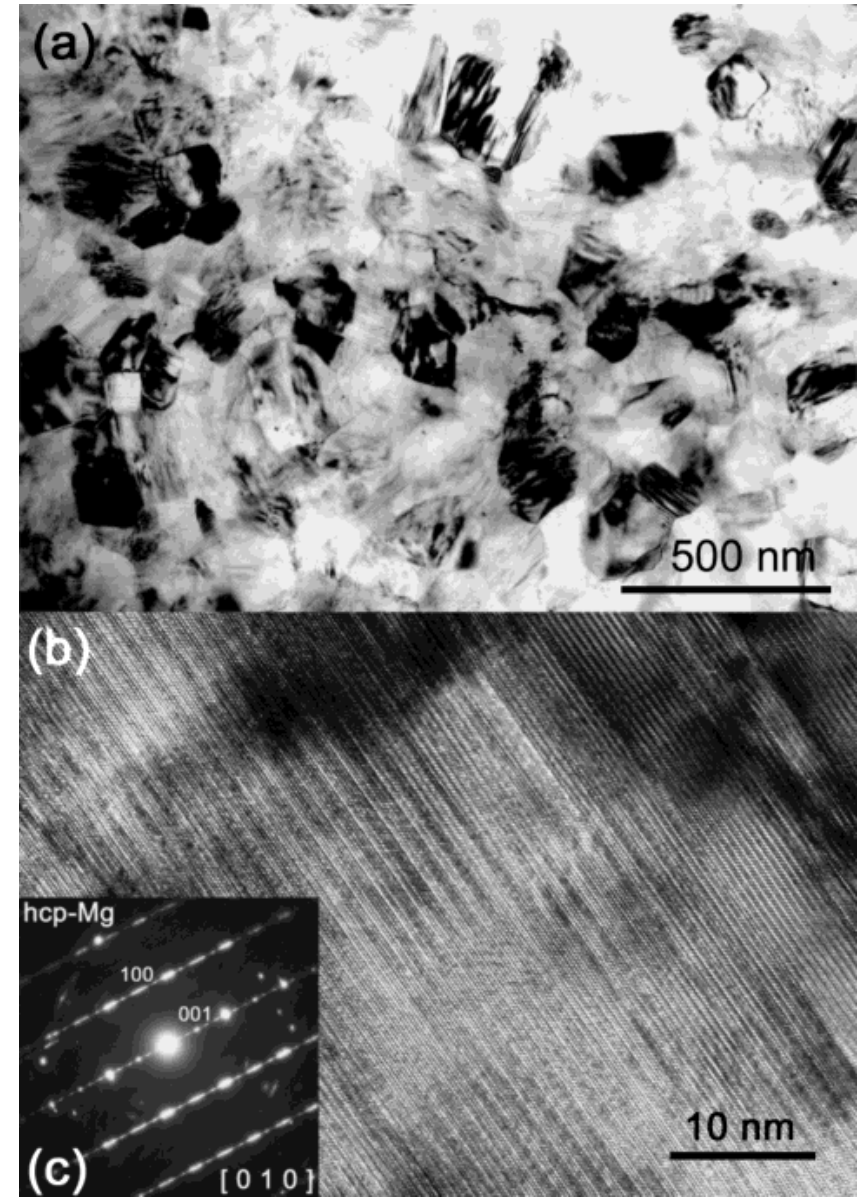

Fig. 3 (a) Bright-field TEM image, (b) high-resolution TEM image and (c) selected-area electron diffraction pattern taken from one grain in (b) for the RS/PM Mg $\mathrm{Mg}_{97} \mathrm{Zn}_{1} \mathrm{Y}_{2}$ alloy produced at $T_{\mathrm{e}}=573 \mathrm{~K}$.

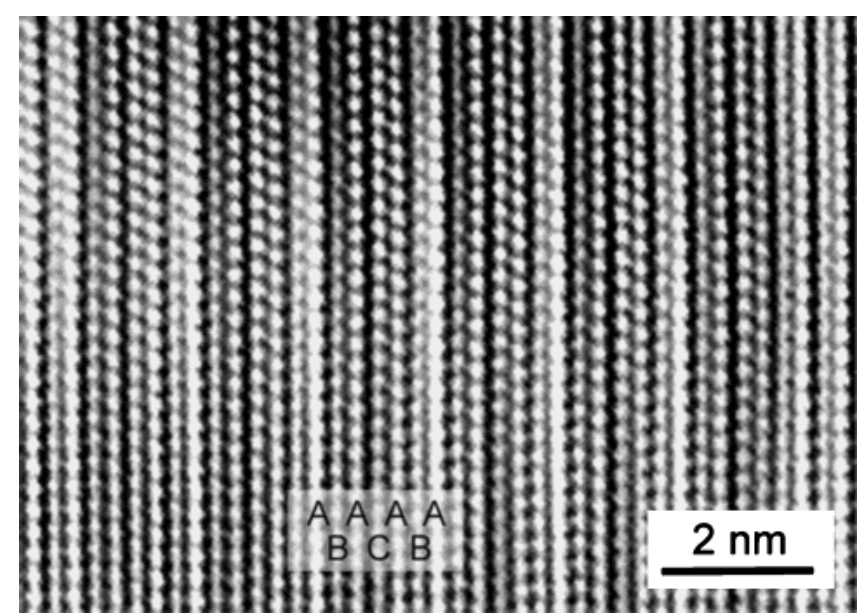

Fig. 4 High-resolution TEM image of the RS/PM $\mathrm{Mg}_{97} \mathrm{Zn}_{1} \mathrm{Y}_{2}$ alloy produced at $T_{\mathrm{e}}=573 \mathrm{~K}$.

those for the RS/PM $\mathrm{Mg}_{97} \mathrm{Zn}_{1} \mathrm{Y}_{2}$ alloy. We further examined the plane faulted structure by the high resolution TEM technique. Figure 6 shows its high-resolution TEM image and selected-area electron diffraction pattern. Although two layered packing arrays corresponding to the ordinary ABABAB type atomic configuration are seen in the right- and left-hand sides in the TEM image, the faulted region in the central area has a longer periodic atomic configuration. As is evident from the diffraction pattern as well as from the high-

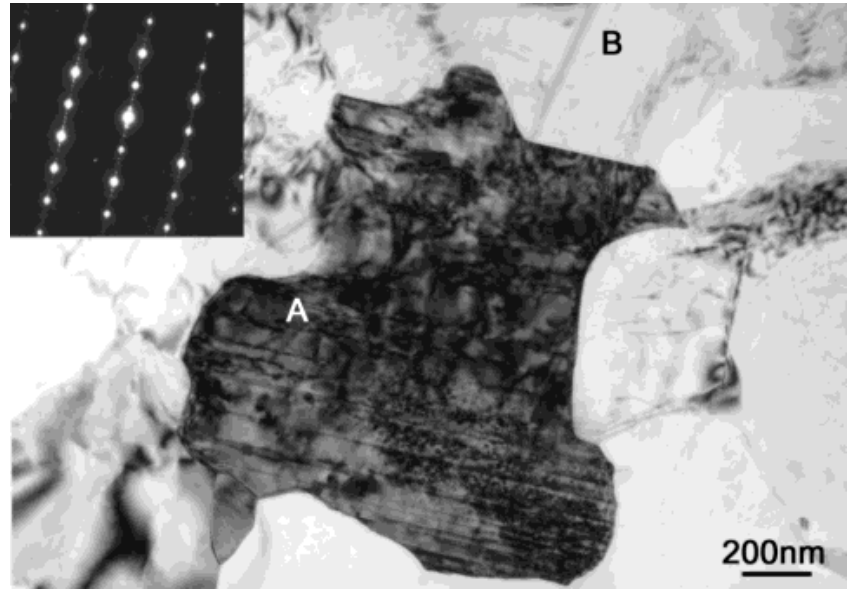

Fig. 5 Bright-field TEM image and selected-area electron diffraction pattern taken from the grain A for the melt-spun $\mathrm{Mg}_{97} \mathrm{Zn}_{1} \mathrm{Y}_{2}$ alloy ribbon.

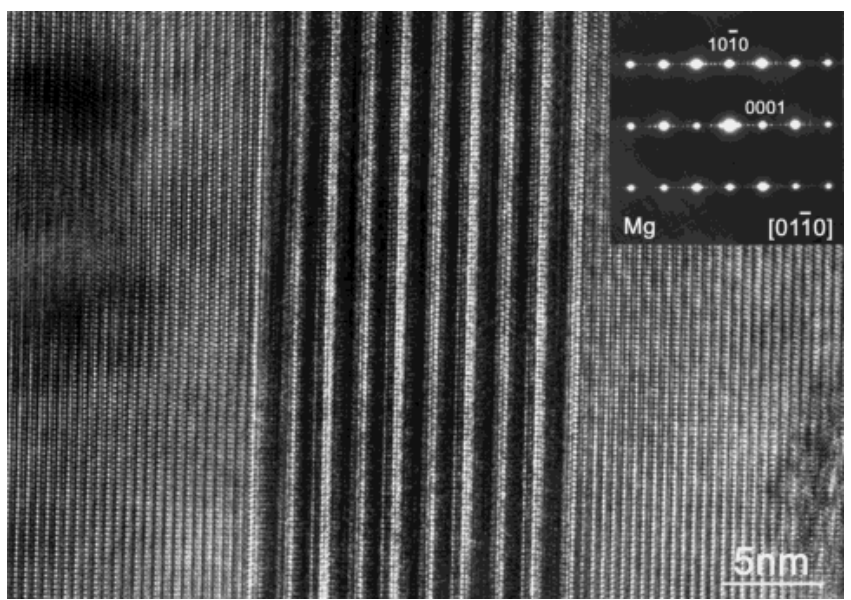

Fig. 6 High-resolution TEM image and selected-area electron diffraction pattern of the melt-spun $\mathrm{Mg}_{97} \mathrm{Zn}_{1} \mathrm{Y}_{2}$ alloy ribbon.

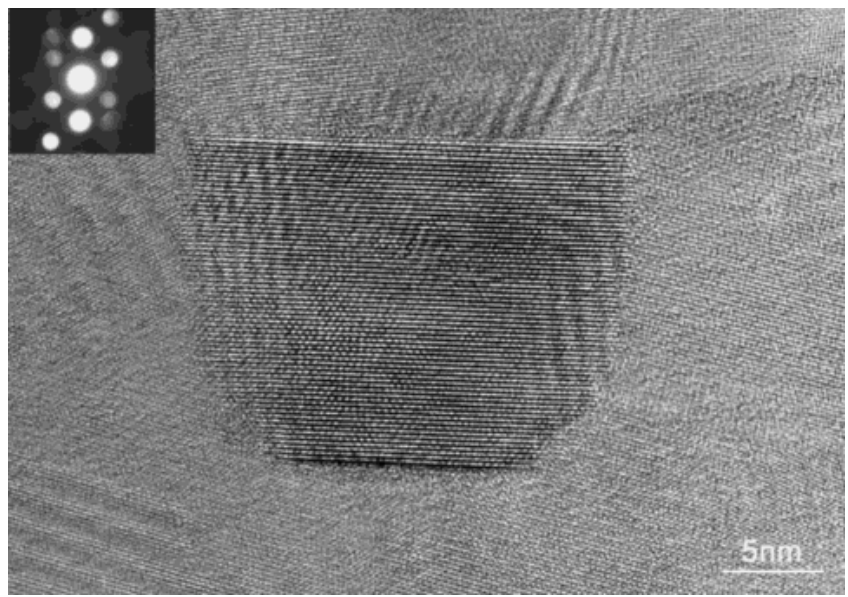

Fig. 7 High resolution TEM image and nanobeam electron diffraction pattern taken from the precipitation phase for the melt-spun $\mathrm{Mg}_{97} \mathrm{Zn}_{1} \mathrm{Y}_{2}$ alloy ribbon.

resolution image, the periodicity of atomic configurations along the $[0001]_{\mathrm{Mg}}$ direction is seven times longer than that for the ordinary hexagonal phase. The periodicity is much longer than that for the RS/PM $\mathrm{Mg}_{97} \mathrm{Zn}_{1} \mathrm{Y}_{2}$ alloy shown in Fig. 4. The difference indicates that the periodicity is not always fixed and depends on the preparation condition of the alloy. That is, the atomic configurations in the faulted region 

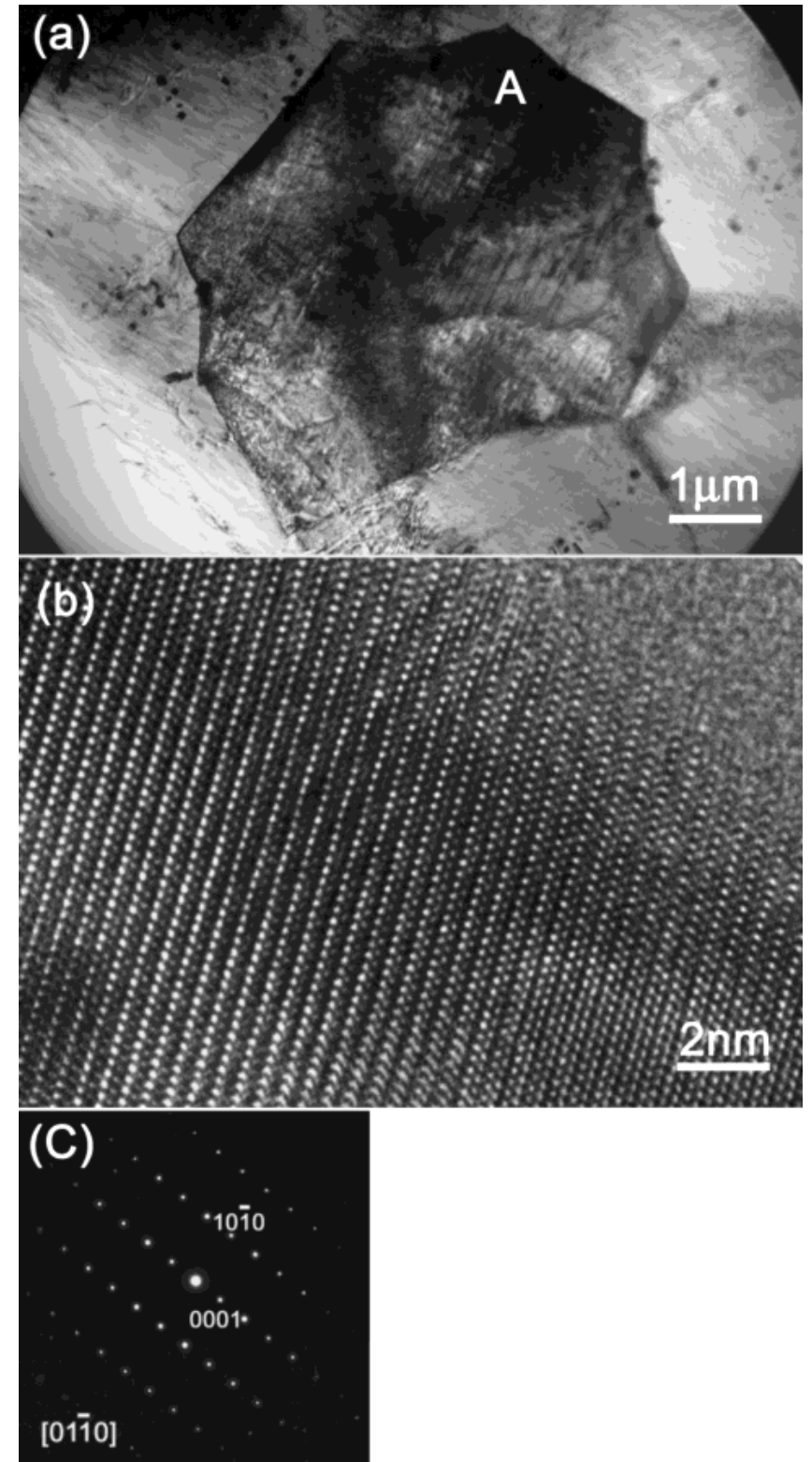

Fig. 8 (a) Bright-field TEM image, (b) high-resolution TEM image of grain A in (a), and (c) selected-area electron diffraction pattern taken from the grain $\mathrm{A}$ for the melt-spun $\mathrm{Mg}_{98} \mathrm{Y}_{2}$ alloy ribbon.

are sensitive to strain and solute content in the hexagonal solid solution. Here, it is important to clarify the relation between the plane fault and the precipitation site of the cubic $\mathrm{Mg}_{24} \mathrm{Y}_{5}$ compound. Figure 7 shows a high-resolution TEM image of the $\mathrm{Mg}_{24} \mathrm{Y}_{5}$ compound in the melt-spun $\mathrm{Mg}_{97} \mathrm{Zn}_{1} \mathrm{Y}_{2}$ alloy ribbon, together with the nanobeam electron diffraction pattern taken from the compound. Although the plane faulted region marked with $\mathrm{A}$ is seen at the lower left-hand side in the TEM image, the $\operatorname{Mg}_{24} \mathrm{Y}_{5}$ compound precipitates at the place which is slightly away from the plane faulted region. We could not obtain a direct evidence revealing that the $\mathrm{Mg}_{24} \mathrm{Y}_{5}$ compound precipitates preferentially in the plane faulted region. The absence of the close correlation suggests that the plane faults in the $\mathrm{Mg}$ solid solution are introduced at relatively low temperatures after the $\mathrm{Mg}_{24} \mathrm{Y}_{5}$ particles precipitated.

Considering that such a long periodic hexagonal phase had not been reported in any kinds of $\mathrm{Mg}$-based alloys, we tried
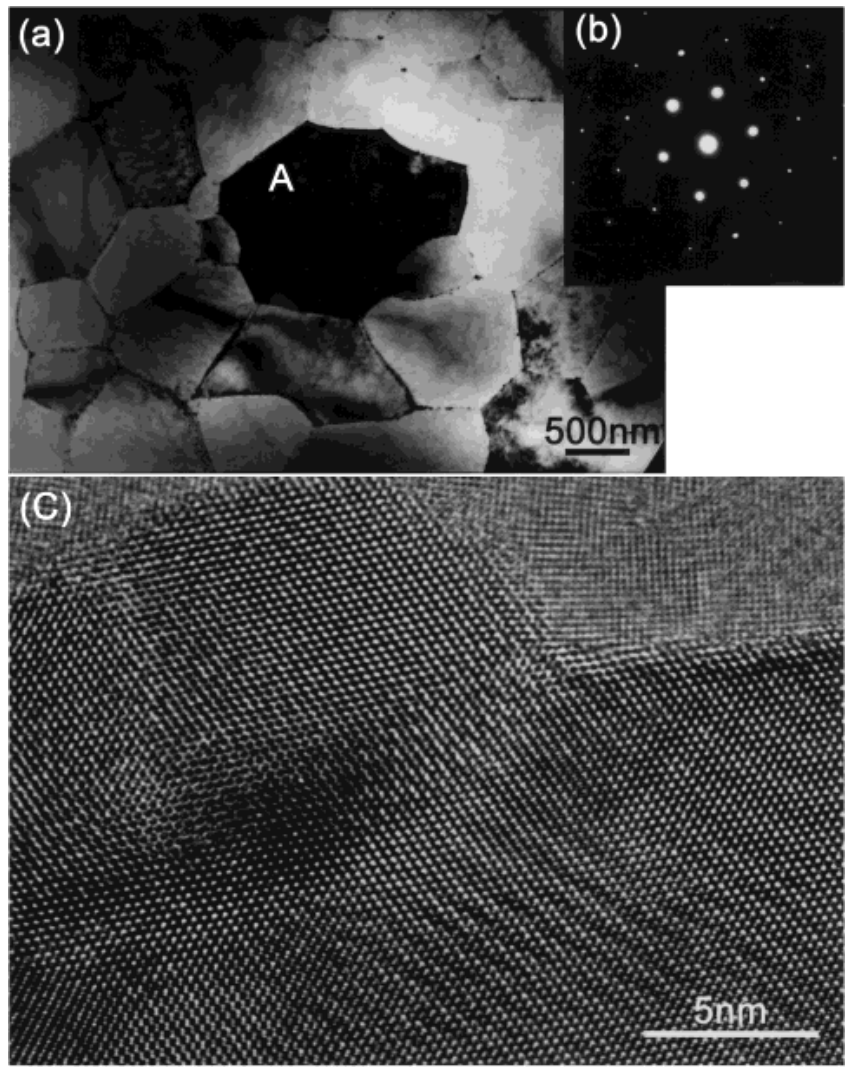

Fig. 9 (a) Bright-field TEM image, (b) selected-area electron diffraction pattern taken from grain $\mathrm{A}$ in (a), and (c) high-resolution TEM image of the grain $\mathrm{A}$ for the melt-spun $\mathrm{Mg}_{97} \mathrm{Al}_{1} \mathrm{Y}_{2}$ alloy ribbon.

to clarify the alloy system in which the novel long periodic hexagonal phase is formed in the melt-spun state. Figures 8(a), (b) and (c) show bright-field image, high-resolution TEM image and selected-area diffraction pattern taken from the region in (b), respectively, for the melt-spun $\mathrm{Mg}_{98} \mathrm{Y}_{2}$ alloy. No plane faults are seen in the ordinary bright-field image (a), though fine $\mathrm{Mg}_{24} \mathrm{Y}_{5}$ precipitates with a size of about $50 \mathrm{~nm}$ are observed in all the grains. In addition, no extra reflection spots along the $[0001]_{\mathrm{Mg}}$ direction are also seen and the $\mathrm{ABABAB}$ type atomic configurations are clearly seen in the high resolution TEM image. We have also confirmed the absence of plane faults in the melt-spun $\mathrm{Mg}_{98} \mathrm{Zn}_{2}$ alloy by transmission electron microscopy. These results indicate that the dissolution of only $\mathrm{Y}$ or $\mathrm{Zn}$ into the $\mathrm{Mg}$ solid solution does not generate the plane faulted region with novel longperiodic atomic configurations. We also examined the possibility of forming the plane faults in a melt-spun $\mathrm{Mg}_{97} \mathrm{Al}_{1} \mathrm{Y}_{2}$ alloy. Figures 9(a), (b) and (c) show the bright-field image, selected-area electron diffraction pattern taken from the grain A in (a), and high-resolution TEM image of the grain A. No plane faults are seen in all the grains. The high resolution TEM image also reveals the absence of the novel long periodic atomic configuration region. Here, it is important to point out that some precipitates lie preferentially along the grain boundary of the $\mathrm{Mg}$ phase. This is in good contrast to the result that the $\mathrm{Mg}_{24} \mathrm{Y}_{5}$ compound in the $\mathrm{Mg}_{97} \mathrm{Zn}_{1} \mathrm{Y}_{2}$ and $\mathrm{Mg}_{98} \mathrm{Y}_{2}$ alloys lied inside the grains and no grain boundary precipitation was observed. The difference in the precipitation site of the second phase between the $\mathrm{Mg}-\mathrm{Zn}-\mathrm{Y}$ and $\mathrm{Mg}-$ 
Al-Y alloys may be the origin for the high tensile strength combined with good ductility only for the $\mathrm{Mg}-\mathrm{Zn}-\mathrm{Y}$ alloy. With the aim of confirming the reduction of the solute content in the $\mathrm{Mg}$ solid solution by the precipitation of the second phase along the grain boundary in the $\mathrm{Mg}-\mathrm{Al}-\mathrm{Y}$ system and determining the component of the precipitates, the EDX spectroscopy was made for the melt-spun $\mathrm{Mg}_{97} \mathrm{Al}_{1} \mathrm{Y}_{2}$ alloy. The average solute composition obtained from five different sites in the matrix phase was 0.42 at $\% \mathrm{Al}$ and 1.68 at $\% \mathrm{Y}$ which is considerably lower than that $(0.78$ at $\% \mathrm{Zn}$ and 1.82 at $\% \mathrm{Y})$ for the $\mathrm{Mg}_{97} \mathrm{Zn}_{1} \mathrm{Y}_{2}$ alloy. On the other hand, the EDX spectroscopic data taken from the second precipitates along the grain boundary indicate that the solute components have significant scattering ranging from 1.85 to 19.6 at $\% \mathrm{Al}$ and 4.71 to 22.1 at $\%$ Y, implying the existence of several kinds of precipitates. It is thus concluded that the supersaturation level of the Mg-based solid solution is considerably higher for the $\mathrm{Mg}-$ $\mathrm{Zn}-\mathrm{Y}$ hexagonal phase.

\section{Discussion}

As decribed above, the RS/PM $\mathrm{Mg}_{97} \mathrm{Zn}_{1} \mathrm{Y}_{2}$ alloy had the following structural features; (1) fine grain size, (2) novel long periodic hexagonal structure of ABACAB type packing with lattice parameters of $a=0.322 \mathrm{~nm}$ and $c=3 \times$ $0.521 \mathrm{~nm}$, (3) reinforced dissolution of $\mathrm{Zn}$ and $\mathrm{Y}$, and (4) homogeneous dispersion of fine cubic $\mathrm{Mg}_{24} \mathrm{Y}_{5}$ precipitates inside the grains. The maximum solid solubility of each solute element into hcp $\mathrm{Mg}$ phase in the $\mathrm{Mg}$-based binary systems is $0.07 \mathrm{at}^{7)}$ for $\mathrm{Zn}$ and nearly zero ${ }^{8)}$ for $\mathrm{Y}$ at room temperature. In addition, there is no appreciable solid solubility of $\mathrm{Zn}$ and $\mathrm{Y}$ into hcp $\mathrm{Mg}$ phase in $\mathrm{Mg}-\mathrm{Zn}-\mathrm{Y}$ ternary system. ${ }^{9)}$ In addition, no plane faults leading to the generation of the novel long periodic atomic configurations was observed in the meltspun $\mathrm{Mg}_{98} \mathrm{Y}_{2}$ and $\mathrm{Mg}_{98} \mathrm{Zn}_{2}$ binary and $\mathrm{Mg}_{97} \mathrm{Al}_{1} \mathrm{Y}_{2}$ ternary alloys. Consequently, the long periodic hexagonal phase is a metastable solid solution saturated simultaneously with $\mathrm{Zn}$ and $\mathrm{Y}$. It is also recognized that the fine $\mathrm{Mg}_{24} \mathrm{Y}_{5}$ compound particles in the RS/PM $\mathrm{Mg}_{97} \mathrm{Zn}_{1} \mathrm{Y}_{2}$ and melt-spun $\mathrm{Mg}_{98} \mathrm{Y}_{2}$ alloys precipitate inside the grains and no grain boundary precipitates are seen in both the alloys, while all the precipitates in the melt-spun $\mathrm{Mg}_{97} \mathrm{Al}_{1} \mathrm{Y}_{2}$ alloy lie preferentially along the grain boundary. Furthermore, there was no correlation between the precipitation site of the $\mathrm{Mg}_{24} \mathrm{Y}_{5}$ compound and the plane faulted region in the $\mathrm{Mg}-\mathrm{Zn}-\mathrm{Y}$ alloy. Based on the structural features obtained in the present study, the high strength seems to be due to the combination of (1) strengthening by the grain size refinement, (2) solid solution strengthening, (3) introduction of a high density of plane faults leading to the formation of the long periodic hexagonal phase, and (4) dispersion strengthening due to the homogeneous precipitation of the fine compound particles. In addition, the good ductility may be attributed to the above-described favorable structure such as the fine grain size, the absence of precipitates on the grain boundary and the fine particle size, homogeneous dispersion and small volume fraction of the $\mathrm{Mg}_{24} \mathrm{Y}_{5}$ compound.

Finally, we discuss the reason for the generation of the novel long periodic hexagonal atomic configurations only in the Mg-based solid solution containing simultaneously $\mathrm{Zn}$ and $\mathrm{Y}$ elements. The atomic size ratios of the constituent elements in the $\mathrm{Mg}-\mathrm{Zn}-\mathrm{Y}$ and $\mathrm{Mg}-\mathrm{Al}-\mathrm{Y}$ alloys are 1.13 for $\mathrm{Y} / \mathrm{Mg}, 1.14$ for $\mathrm{Mg} / \mathrm{Zn}$ and 1.12 for $\mathrm{Mg} / \mathrm{Al}$ and the heats of mixing among their elements are $-13 \mathrm{KJ} / \mathrm{mol}$ for $\mathrm{Mg}-\mathrm{Zn}$ pair, $-27 \mathrm{~kJ} / \mathrm{mol}$ for $\mathrm{Mg}-\mathrm{Y},-105 \mathrm{~kJ} / \mathrm{mol}$ for $\mathrm{Zn}-\mathrm{Y}$, $-7 \mathrm{~kJ} / \mathrm{mol}$ for $\mathrm{Mg}-\mathrm{Al}$ and $-132 \mathrm{~kJ} / \mathrm{mol}$ for $\mathrm{Al}-\mathrm{Y}$. One can notice that the significant atomic size mismatches exceeding $12 \%$ and the negative heats of mixing agree with the empirical criteria for stabilization of supercooled liquid as well as for formation of bulk glassy alloys. The agreement may be one of the origins for the formation of the novel long periodic hexagonal solid solution in the $\mathrm{Mg}-\mathrm{Zn}-\mathrm{Y}$ system. That is, the stabilized supercooled liquid of the $\mathrm{Mg}-\mathrm{Zn}-\mathrm{Y}$ alloy can dissolve a larger amount of solute elements in spite of the significant atomic size mismatches, leading to the generation of significant lattice strains. It can be therefore interpreted that the change in the atomic configurations into the long periodic type was introduced for the relaxation of the significant lattice strains. The degree of the satisfaction for the three empirical rule is considerably lower for the $\mathrm{Mg}-\mathrm{Al}-\mathrm{Y}$ alloy and the $\mathrm{Al}-$ $\mathrm{Y}$ atomic pair has a much larger negative value as compared with those for the other atomic pairs. The lower degree of satisfaction for the three empirical criteria leads to the easy precipitation of the second phase along the grain boundary, resulting in a decrease in the solute content in the $\mathrm{Mg}$ solid solution as well as a reduction of lattice strains.

\section{Conclusions}

The RS/PM $\mathrm{Mg}_{97} \mathrm{Zn}_{1} \mathrm{Y}_{2}$ bulk alloy was found to have the highest specific strength ratio $\left(\sigma_{\mathrm{y}} / \rho\right)$ among all metallic materials. It is therefore expected that the new Mg-based bulk alloy is used in many fields and contributes to the saving of energy and the resulting reduction of carbon dioxide gas. Besides, the alloy was characterized to consist mainly of a $\mathrm{Mg}$ supersaturated solid solution with novel long periodic hexagonal structure. The novel long periodic hexagonal phase was also observed in the melt-spun $\mathrm{Mg}_{97} \mathrm{Zn}_{1} \mathrm{Y}_{2}$ alloy ribbon. The formation of the novel $\mathrm{Mg}$-based solid solution in the $\mathrm{Mg}$ $\mathrm{Zn}-\mathrm{Y}$ system indicates the possibility of fabricating a new structural phase with useful properties by the reinforced solution of more than two kinds of solute elements with significantly different atomic size mismatches and negative heats of mixing.

\section{REFERENCES}

1) Metals Handbook, ed. by Japan Inst., (Metals, Maruzen, Tokyo, 2000) pp. 572-577.

2) A. Inoue: Mater. Trans., JIM 36 (1995) 866-875.

3) A. Inoue: Bulk Amorphous Alloys, (Trans Tech Publications, Zurich 1998) pp. 1-116.

4) A. Inoue: Acta Mater. 48 (2000) 279-306.

5) A. Inoue, Y. Kawamura, M. Matsushita, K. Hayashi and J. Koike: J. Mater. Res. 16 (2001) 1894-1900.

6) A. Kato, T. Suganuma, H. Horikiri, Y. Kawamura, A. Inoue and T. Masumoto: Mater. Sci. Eng. A179/A180 (1994) 112-117.

7) J. B. Clark, L. Zabdyr and Z. Moser: Phase Diagrams of Binary Magnesium Alloys, ASM, (Metals Park, Ohio, 1988) pp. 353-364.

8) A. A. Nayeb-Hashemi and J. B. Clark: Phase Diagrams of Binary Magnesium Alloys, ASM, (Metals Park, Ohio, 1988) pp. 344-349.

9) P. Villars, A. Prince and H. Okamoto: Handbook of Ternary Phase Diagrams, ASM International, (Metals Park, Ohio, 1995) pp. 12369-12372. 